\title{
Different effects of Wnt/ $\beta$-catenin activation and PTH activation in adult and aged male mice metaphyseal fracture healing
}

\author{
Daocheng Liu, Hao Qin, Jiazhi Yang, Lei Yang, Sihao He, Sixu Chen, Quanwei Bao, Yufeng Zhao and \\ Zhaowen Zong ${ }^{*}$ (iD
}

\begin{abstract}
Background: Fractures in older men are not uncommon and need to be healed as soon as possible to avoid related complications. Anti-osteoporotic drugs targeting Wnt/ $\beta$-catenin and PTH (parathyroid hormone) to promote fracture healing have become an important direction in recent years. The study is to observe whether there is a difference in adult and aged situations by activating two signal paths.

Methods: A single cortical hole with a diameter of $0.6 \mathrm{~mm}$ was made in the femoral metaphysis of Catnb ${ }^{\text {lox(ex3) }}$ mice and wild-type mice. The fracture healing effects of CA (Wnt/B-catenin activation) and PTH (activated by PTH (1-34) injections) were assessed by X-ray and CT imaging on days 7, 14, and 21 after fracture. The mRNA levels of $\beta$-catenin, PTH1R(Parathyroid hormone 1 receptor), and RUNX2(Runt-related transcription factor 2) in the fracture defect area were detected using RT-PCR. Angiogenesis and osteoblasts were observed by immunohistochemistry and osteoclasts were observed by TRAP (Tartrate-resistant Acid Phosphatase).

Result: Adult CA mice and adult PTH mice showed slightly better fracture healing than adult wild-type (WT) mice, but there was no statistical difference. Aged CA mice showed better promotion of angiogenesis and osteoblasts and better fracture healing than aged PTH mice.
\end{abstract}

Conclusion: The application of Wnt/ $\beta$-catenin signaling pathway drugs for fracture healing in elderly patients may bring better early effects than PTH signaling pathway drugs, but the long-term effects need to be observed.

Keywords: Wnt/ß-catenin, PTH, Fracture healing, Adult, Aged

\section{Background}

Over 100,000 fractures are sustained every year in the UK by people of all ages and sexes [1]. Nonunion is an important complication of fractures. The most common risk factors include diabetes, increased age, osteoporosis, excessive alcohol consumption, blood circulation, and non-steroidal anti-inflammatory drugs (NSAIDs) [2]. Metaphyseal fractures are a major occurrence; hip fractures account for $3.5 \%$ of fractures in older women and $2.6 \%$ in older men [3]. More attention has been given to

\footnotetext{
* Correspondence: zongzhaowen@tmmu.edu.cn

State Key Laboratory of Trauma, Burn and Combined Injury, Department of War Wound Rescue Skills Training, Base of Army Health Service Training, Army Medical University, Chongqing 400042, China
}

estrogen-related osteoporotic fractures in older women, while osteoporotic fractures in older men have been studied less frequently $[4,5]$. Decreased bone mineral density may lead to osteoporotic fractures, which occur frequently in both older men and women. Male predisposing factors include reduced body mass index, family history of osteoporosis, and increased age $[6,7]$.

The mechanisms underlying fracture healing are of utmost importance for delineating the possible causes of impaired bone repair, as well as for identifying pharmaceutical agents that could be used to accelerate the healing process and increase bone union rates. Physiological bone repair involves a complex series of events.

(c) The Author(s). 2020 Open Access This article is distributed under the terms of the Creative Commons Attribution 4.0 International License (http://creativecommons.org/licenses/by/4.0/), which permits unrestricted use, distribution, and 
In recent years, Wnt/ $\beta$-catenin activation and $\mathrm{PTH}$ (parathyroid hormone) have been studied for the treatment of osteoporosis and the promotion of fracture healing. The classical Wnt/ $\beta$-catenin signaling pathway plays an important role in bone regeneration and remodeling in mice and humans. While activation of the Wnt/ $\beta$-catenin signaling pathway cannot prevent or treat osteoporosis, it can promote fracture healing [8-10]. PTH has been widely used clinically in the treatment of osteoporosis. Recently, some studies have found that intermittent low-dose parathyroid hormone can promote fracture healing in animals and humans and firm the fixation of the implants [11-17]. Although the two signaling pathway are known to have a role in promoting fracture healing, it is unclear whether their effects are the same at different ages of the patient. Observing the effects of activating two signaling pathways that promote fracture healing in both adult and elderly patients will provide some guidance for the clinical selection of drugs for patients of different ages, especially in the early stages of fracture. In particular, promoting fracture healing is an urgent need for elderly patients.

\section{Methods}

Animals

All animal procedures were approved by the Laboratory Animal Welfare and Ethics Committee of the Third Military Medical University of China and were conducted in accordance with procedures approved by the institution. The TM-inducible Cre fusion protein CreERTM expression is under the control of a $3.2 \mathrm{~kb}$ mouse procollagen 1 promoter $(3.2 \mathrm{~kb}$ Col1-Cre). ERTM crossed with Catnb+/flox (exon 3) mice (obtained from Feng Jianquan, Department of Biomedical Sciences, Baylor Dental University, USA) [15], and genotype mice without expressed in littermates. The $3.2 \mathrm{~kb}$ Col1-Cre ERTM/ $\beta$-catenin exon $3 \mathrm{fx}+/+$ activates the $\beta$-catenin signaling pathway in mouse osteoblasts by TM injection $[18,19]$. Genotyping was performed with a routine method. Briefly, DNA was extracted from the toe of each mouse using a standard protocol, and subjected to PCR for genotyping. The PCR primers for Cre were 5'CCCGCAGAACCTGAAGATG-3' (sense) and 5' GACCCGGCAAAACAGGTAG-3' (anti-sense), and the PCR primers for Catnb+/lox (exon3) mice were $5^{\prime}$ AGGGTACCTGAAGCTCAGCG-3' (sense) and 5' CAGTGGCTGACAGCAGCTTT-3' (anti-sense).

\section{Animal surgical procedures}

A single cortical bone defect was made in the right femoral metaphysis of all mice. The mice were anesthetized with $1 \%$ pelltobarbitalum natricum at a dose of $50 \mathrm{mg} /$ $\mathrm{kg}$. The right hind limb fur was shaved, the skin was disinfected, and then a towel was spread in preparation for surgery. A $10 \mathrm{~mm}$ incision was made over the right hind limb knee joint. The muscles were bluntly separated, and the periosteum was dissected while taking care to protect the joint cavity. An electric drill with a steel drill bit (Fine Science Tools \#19007-07) with a diameter of $0.6 \mathrm{~mm}$ was used to drill a single $2-\mathrm{mm}$ cortical defect on the articular surface. The drill bit was transferred into the marrow (medullary) cavity but did not break through the contralateral cortex [20-23]. Heat lamps were used to maintain the body temperature of the mice during their recovery from anesthesia.

\section{Animal groups}

Six-month-old and 12-month-old male mice with the Catn$b^{\operatorname{lox}(e x 3)}$ gene background and wild-type (WT) male littermates were divided into six groups and their femoral metaphysis fractured: adult WT group (6-month-old wildtype mice injected with saline, $n=12$ ), adult PTH group (6month-old wild-type mice injected with PTH (1-34), $n=$ 8 ), and the adult CA (Wnt/ $\beta$-catenin activation) group (6month-old Catnb ${ }^{\text {lox (ex3) }}$ mice injected with tamoxifen, $n=$ 8); aged WT group (12-month-old wild-type mice injected with normal saline, $n=12$ ), aged PTH group (12-monthold wild-type mice injected with PTH $(1-34), n=8)$, and the aged CA group (12-month-old Catnb ${ }^{\operatorname{lox}(\mathrm{ex} 3)}$ mice injected with tamoxifen, $\mathrm{n}=8$ ). The adult and aged PTH mice were injected daily intraperitoneally (concentration $1 \mu \mathrm{g} / \mathrm{ml}$, dose $80 \mu \mathrm{g} / \mathrm{kg}$ body weight) with PTH (1-34) (Sigma, US) before the mice were sacrificed (7 days, 14 days, and 21 days). At the same time points, the same volume of physiological saline was administered to adult and aged WT mice by intraperitoneal injection. The adult and aged CA mice were injected with TM ( $75 \mathrm{mg} / \mathrm{kg}$ body weight) after surgery to activate $\beta$-catenin. To observe cell proliferation, 5 '-bromo-2-deoxyuridine (BrdU, Sigma, Ireland) was intraperitoneally injected ( $10 \mu \mathrm{L} / \mathrm{g}$ body weight) $1 \mathrm{~h}$ and 3 days before the mice were over-anesthetized.

\section{Tissue preparation}

Mice were sacrificed using an excess of anesthetic by Using intraperitoneal injection of sodium pentobarbital $200 \mathrm{mg} / \mathrm{kg}$ on days 7, 14, and 21 after the fracture, and RNA from the fracture area was extracted. X-ray examination was performed on the right femur of each group of four mice. These femurs were then fixed overnight using formalin and micro-CT was performed the next day. The femurs were decalcified in $10 \%$ ethylenediaminetetraacetic acid. After successful decalcification, they were tissueembedded and sectioned (thickness: $4 \mu \mathrm{m}$ ). The sections were dewaxed to water and then histologically stained and immunohistochemically stained.

\section{X-ray and CT scan}

$\mathrm{X}$-ray examination and CT examination analysis have been widely used to assess fracture healing. The right 
femur X-ray image was taken on days 7, 14, and 21 following the procedure using the Faxitron system (Faxitron X-ray, Wheeling, IL, USA) [24, 25]. The right femur was examined using a Viva CT 40 (Scanco Medical, Bassersdorf, Switzerland, Switzerland) according to the procedure recommended by the American Society for Bone and Mineral Research [16]. In the examination, the femur was placed in an eppendorf tube filled with ethanol. The X-ray tube potential was $45 \mathrm{kVp}$, and the voxel size was $10 \mu \mathrm{m}^{3}$. The obtained image was analyzed and three-dimensionally reconstructed using EVS Beam software (1400 Hounsfield unit was set to bone) [23]. The area centered on the defect center with a diameter of $0.8 \mathrm{~mm}$ and a depth of $0.4 \mathrm{~mm}$ was set as the region of interest, and the percentage of bone volume to total volume (BV/TV) was calculated.

\section{Hematoxylin-eosin staining}

Hematoxylin-eosin (H\&E) staining was performed using the previously used procedure [18]. Briefly, tissue sections were deparaffinized to water, stained with hematoxylin for $5 \mathrm{~min}$, and then differentiated with ethanolic ethanol over alkaline water. Tissue sections were stained with eosin for $15 \mathrm{~s}$ and then dehydrated for $2 \mathrm{~min}$ (twice) with 95\% ethanol and then with $100 \%$ alcohol for 3 min (twice). The sections were then cleared with xylene. The slides were sealed with neutral gum [23].

\section{Masson's staining for collagen}

The sections were dewaxed in xylene, hydrated, stained with Weigert hematoxylin for $10 \mathrm{~min}$, rinsed with distilled water, stained with Masson's limonic acid solution for $10 \mathrm{~min}$, and immersed in $2 \%$ glacial acetic acid in water. The cells were differentiated in a $1 \%$ aqueous solution of phosphomolybdic acid for $5 \mathrm{~min}$, stained with aniline blue for $5 \mathrm{~min}$, immersed in $0.2 \%$ aqueous glacial acetic acid solution, dehydrated with $95 \%$ alcohol and anhydrous alcohol, and then cleared with xylene before sealing with neutral gum. Blue staining in the microscopic sections indicated collagen fibers.

\section{Real-time polymerase chain reaction (RT-PCR)}

The peri-femoral tissue was removed, approximately $1 \mathrm{~cm}$ of the bone was removed from the center of the fracture defect, and the bone marrow was removed by centrifugation at $5000 \times g$ at $4{ }^{\circ} \mathrm{C}$, and the femur was placed in a mortar containing liquid nitrogen for grinding. The ground tissue was then placed in $1 \mathrm{ml}$ TRIzol reagent to extract the total RNA. The instruments used during the experiment were treated with RNase-free DNase. The expression levels of $\beta$-catenin, PTH1R, and RUNX2 (runtrelated transcription factor 2) were detected by RT-PCR using the SYBR Green assay. Glyceraldehyde-3-phosphate dehydrogenase (GAPDH) was used as the control, and the expression level of each gene was averaged relative to GAPDH. The data are expressed as the ratio of expression levels [26]. The primers are presented in Table 1.

\section{Immunohistochemical staining}

Immunohistochemistry (IHC) was performed with reference to a previous procedure [27]. The primary antibodies used were goat anti-rabbit osteocalcin $(\mathrm{OCN} ; 1: 400)$, runtrelated transcription factor 2 (RUNX2; 1:200), $\beta$-catenin (1:300), and PTH1R (1:300), and anti-mouse matrix metalloproteinase 9 (MMP9; 1:200), vascular endothelial growth factor (VEGF; 1:200), and goat anti-rat BrdU (1:200). All antibodies were purchased from Santa Cruz Biotechnology Corporation (Santa Cruz, CA, USA). The secondary biotinylated goat anti-mouse, rabbit anti-goat, and goat anti-rabbit IgGs were purchased from Boster (Wuhan, China). Positive expression cells were observed the region of interest with an Olympus microscope, and five random regions within the observation range were selected and counted. Results were identified by positive cell values and standard deviations and used for statistical analysis.

\section{Tartrate-resistant acid phosphatase staining}

Tissue sections were deparaffinized with xylene, hydrated, placed in tartrate-resistant acid phosphatase (TRAP) staining solution at $37^{\circ} \mathrm{C}$ for $30 \mathrm{~min}$, and stored in the dark. Sections were then rinsed with water, stained with methyl green for $5 \mathrm{~min}$, dehydrated with gradient alcohol, cleared with toluene, and then sealed with neutral gum. The chemical reagents were purchased from Chuandong Company (Chongqing, China) [28].

The slice images were observed at a magnification of $200 \times$, and the number of TRAP-positive cells therein was counted in five random regions. The results are displayed as the mean and standard deviation, and statistical analysis was performed.

\section{Statistical analysis}

The experimental data used were repeated $\geq 3$ times and are expressed as the mean \pm standard deviation (BV/TV,

Table 1 Primers used for RT-PCR

\begin{tabular}{lll}
\hline Genes & Primer Forward Sequence(5', 3') & Primer Reverse Sequence \\
\hline$\beta$-catenin & ACGGTGCCGCGCCGCTTATA & TAGCCATTGTCCACGCAGCG \\
RUNX2 & AAGTGCGGTGCAAACTTCT & TCTCGGTGGCTGGTAGTGAG \\
PTH1R & AGCGAGTGCCTCAAGTTCAT & ACAGCGTCCTTCACGAAGAT \\
GAPDH & GAGAAGGCTGGGGCTCATT & CCAATATGATTCCACCCATG \\
OCN & AGGGCAGCGAGGTAGTGA & TGGTGTAGCCGAAAGTCC \\
VEGF & CGATGAAGCCCTGGAGTG & ATGATGGCGTGGTGGTGA
\end{tabular}

Shown are the details of the primers used for RT-PCR, including the forward (F) and reverse (R) sequences. RUNX2 Runt-related transcription factor 2, PTH1R Parathyroid hormone 1 receptor, GAPDH Glyceraldehyde-3-phosphate dehydrogenase, OCN Osteocalcin, VEGF Vascular endothelial growth factor 
RT-PCR, Immunostaining staining and TRAP staining). Statistical analysis was performed using one-way analysis of variance and the paired $t$-test using SPSS 19.0 software. Multiple groups of comparisons were performed by oneway analysis of variance (ANOVA) and post hoc comparisons. When the $p$-value was $<0.05$, it was considered statistically significant between the observation group and the control group.

\section{Results}

The speed of metaphyseal fracture healing in adult CA and PTH mice was faster than in adult WT mice, but this was not statistically different

Compared with adult WT mice, we found that the metaphyseal defects in adult CA mice and adult PTH mice healed more rapidly. X-ray (Fig. 1a) examination and 3D (Fig. 1b) reconstruction images showed that on post- operative day 7, the metaphyseal bone defects of adult CA mice and adult PTH mice began to blur, but in adult WT mice the defects were still clearly observed in the middle. The extent of the metaphyseal bone defect continued to decrease on the 14th day after the fracture and disappeared 21 days after the fracture. Among the groups, it disappeared earliest in the adult CA mice and adult PTH mice.

Micro-CT quantitative examination showed that the percentage of BV/TV (Fig. 1c) in the femoral fracture defect areas of adult CA mice and adult PTH mice was much higher than in the adult WT mice at 14 and 21 days after fracture, which was the same as the X-ray examination. As with the trend of $3 \mathrm{D}$ reconstruction, bone defects in the metaphysis of adult CA mice and adult PTH mice healed earlier than in adult WT mice. However, no statistical difference between the fracture sites of adult CA mice and
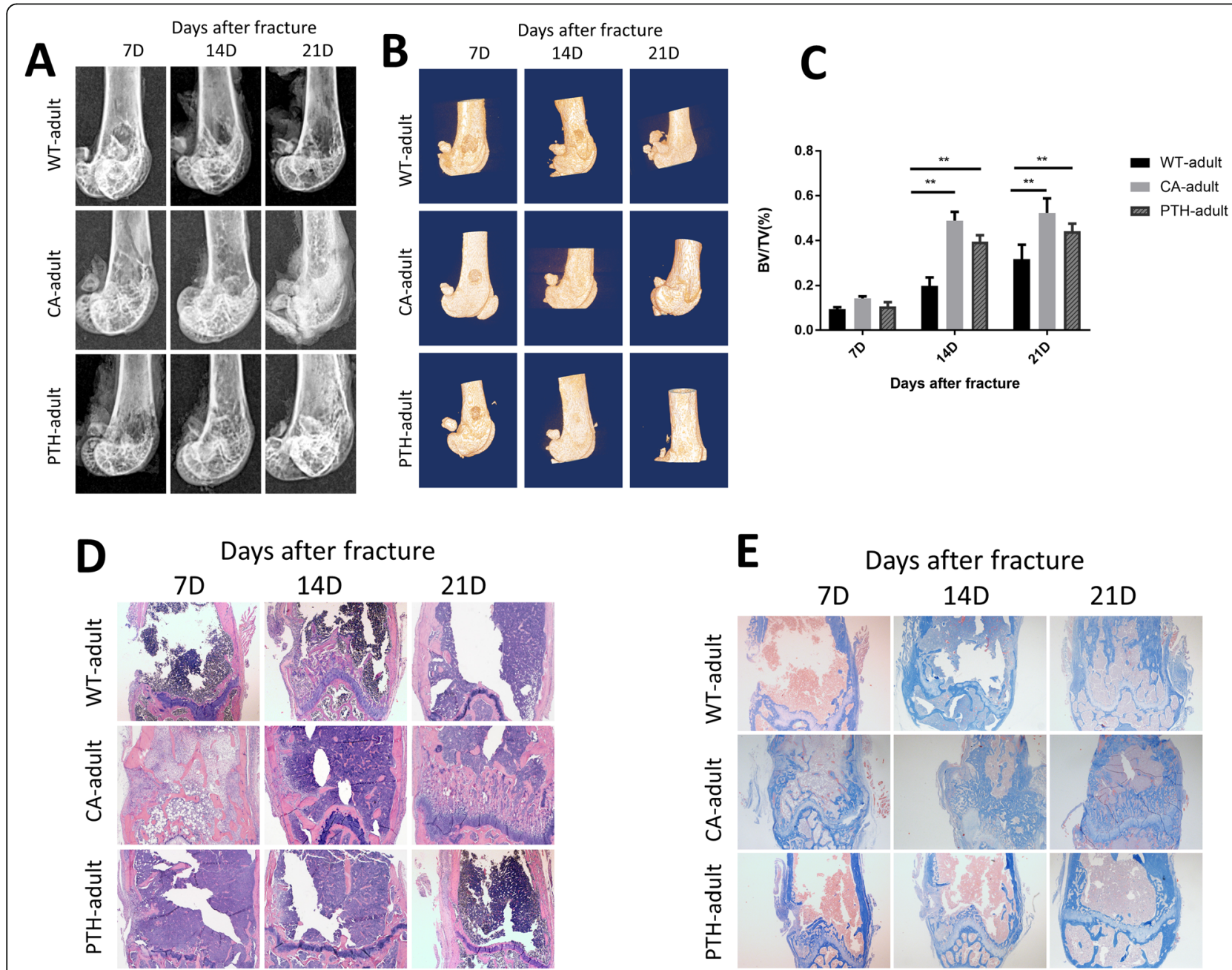

Fig. 1 Defect healing of femoral metaphyseal fractures in adult wild-type (WT-adult) mice, adult Wnt/B-catenin activation (CA-adult) mice, and adult PTH (Parathyroid hormone) activation (PTH-adult) mice. a X-ray, b 3D-CT, $\mathbf{c}$ bone volume/tissue volume (BV/TV) within the region of interest (ROI) was calculated, $\mathbf{d}$ hematoxylin-eosin (H\&E) staining of femurs $(\times 100)$, e Masson's staining of the defect site of femurs $(\times 100)$. The results are expressed as the mean \pm SD; $n=4$ per group; ${ }^{*} P<0.05$ and ${ }^{* *} P<0.01$ 
adult PTH mice was observed at the three time points by observing the percentage of BV/TV (Fig. 1c).

The same trend was observed with the H\&E histological staining (Fig. 1d). On the 7th day after the fracture, soft tissue filling at the metaphyseal fracture defect of adult CA and PTH mice was observed under the microscope; in the adult WT mice, there was still a large gap and soft tissue in the metaphyseal defect. On the 14th day after surgery, more callus filling was seen at the metaphyseal defect of adult CA mice and adult PTH mice, while the metaphyseal end of adult WT mice had only soft tissue filling. On the 21st day after the fracture, healing of the metaphyseal defects in the three groups of mice was close to normal tissue.

Masson staining revealed that collagen fibers in the femoral fracture defect areas of adult CA mice and adult PTH mice were significantly more than in adult WT mice, especially on day 14 after fracture, indicating more callus (Fig. 1e).

The speed of metaphyseal fracture healing in aged CA mice and aged PTH mice was faster than in aged WT mice, and it was faster in aged CA mice than in aged PTH mice

After activation of $\mathrm{Wnt} / \beta$-catenin and $\mathrm{PTH}$, the metaphyseal fracture defects in the aged CA mice and aged PTH mice healed faster than in the aged WT mice, as in the adult mice. X-ray (Fig. 2a) examination and 3D (Fig. 2b) reconstruction of the image suggest that on the 7th day after surgery, the area of the metaphyseal fracture defect in the aged CA mice and aged PTH mice began to become blurred, and the extent of the defect decreased further by the 14th day after surgery and was

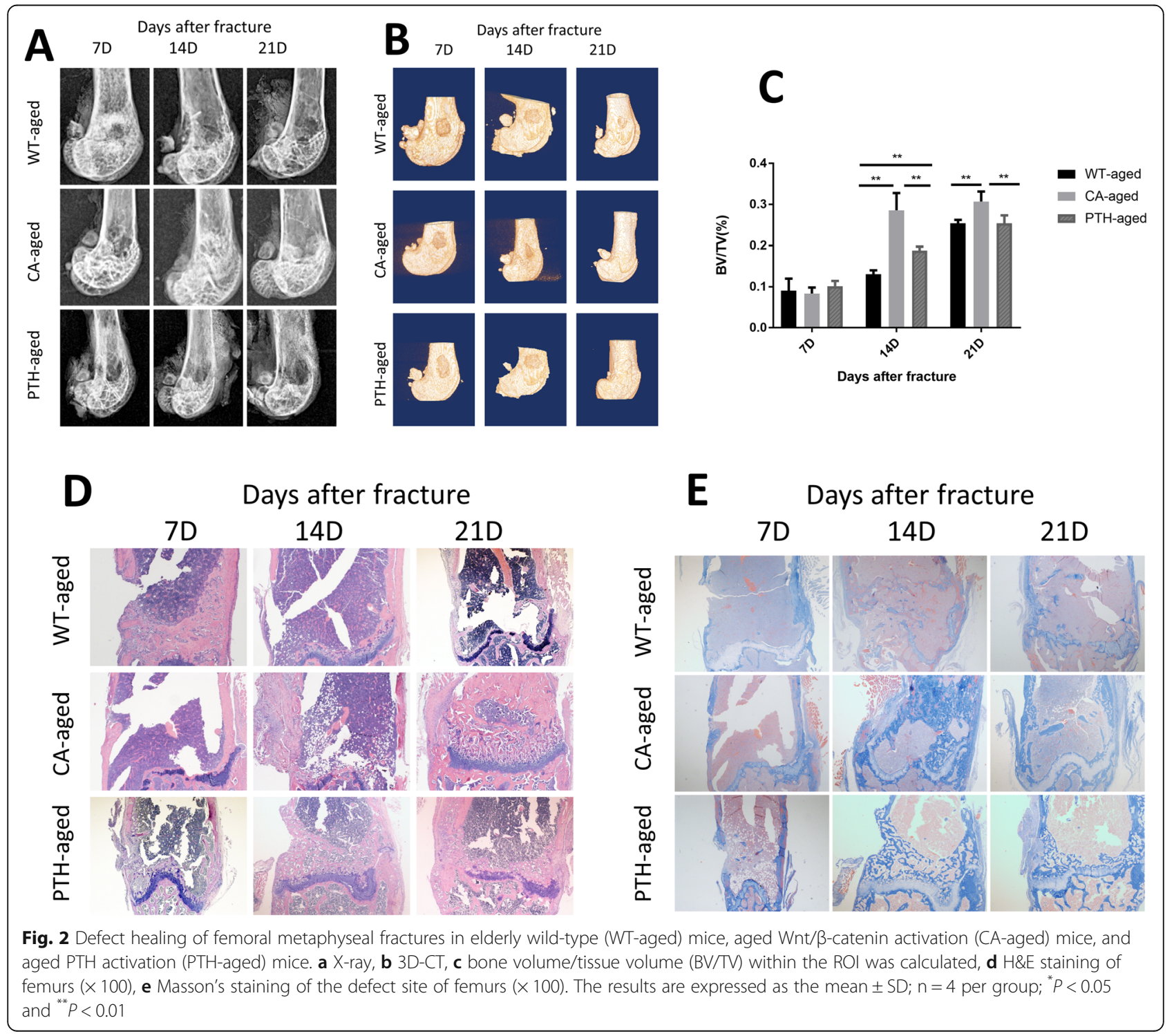


not seen on the 21st day after the fracture. In the aged WT mice, the fracture defect had not changed significantly by the 7th day after fracture, and it was clearly observed on the 14th day after the operation. The reduction was not obvious on the 21st day after the fracture. Among the mouse groups, it was also observed that the area of the fracture defect in the CA mice was smaller than in the aged PTH mice.

Micro-CT examination showed that the percentage of $\mathrm{BV} / \mathrm{TV}$ in the femoral metaphyseal defect area in the aged CA mice was much higher than in the aged WT mice at 14 and 21 days after fracture, and at 14 days after fracture, the percentage of $\mathrm{BV} / \mathrm{TV}$ in the defect of the femoral condyle of the aged PTH mice was higher than in aged WT mice. Interestingly, the percentage of BV/ TV in the femoral metaphyseal defect area in the aged CA mice was higher than in the aged PTH mice at 14 and 21 days after fracture (Fig. 2c).

$H \& E$ staining showed that on the 7 th day after the fracture, the metaphyseal fracture defects of the aged CA mice and aged PTH mice were filled with soft tissue and formed fiber connections, while the aged WT mice still had large metaphyseal defects. On the 14th day after the fracture, the fracture defect area in the aged CA mice and aged PTH mice had formed more osteophytes, while the filling tissues of the aged WT mice were still soft tissue and fibrous tissue (Fig. 2d). On the 21st day after the fracture, the healing of the metaphyseal defect in the aged CA mice was close to that of normal tissue. However, healing of the metaphyseal end in the aged PTH mice was better than in the WT mice but did not reach the healed state.

Masson staining showed that on the 7th day after the fracture, the collagen fibers in the fracture site of the aged CA mice were more than in the aged PTH mice and aged WT mice, and the trend was more obvious on the 14th and 21st days after fracture. The collagen fibers in the aged PTH mice were slightly more than the aged WT mice but did not show a significant advantage (Fig. 2e).

The percentage of BV/TV in the femoral metaphyseal defect area for all tested groups were analyzed. BV/TV were examined with a three-factor ANOVA age, treatment, and time in one omnibus analysis to compare the differences in BV/TV between the adult and aged mice in the six tested groups (Table 2). The probability level of .05 was used to assess statistical significance. There were three main effects and three two-way interactions that were statistically significant. The significant main effects can be ignored as the variables (ie, age, treatment, and time) as they are involved in the significant two-way interactions. Three two-way interactions (age"treatment, age"time and treatment"time) were found statistically significant. This analysis demonstrated that there were consistent statistically significant differences in the BV/
Table 2 A three-factor ANOVA test examining age, treatment and time in one omnibus analysis to compare the differences in healing between the adult and aged studied groups

\begin{tabular}{|c|c|c|c|c|c|}
\hline \multicolumn{6}{|c|}{ Tests of between-subjects effects } \\
\hline \multicolumn{6}{|c|}{ Dependent variable: BV/TV } \\
\hline Source & $\begin{array}{l}\text { Type III sum of } \\
\text { squares }\end{array}$ & df & $\begin{array}{l}\text { Mean } \\
\text { square }\end{array}$ & $\mathrm{F}$ & $\begin{array}{l}\text { Sig. } P \text { - } \\
\text { value }\end{array}$ \\
\hline Corrected model & $1.401^{a}$ & 17 & .082 & 82.515 & .000 \\
\hline Intercept & 4.310 & 1 & 4.310 & 4314.074 & .000 \\
\hline age & .228 & 1 & .228 & 227.739 & .000 \\
\hline treatment & .186 & 2 & .093 & 93.052 & .000 \\
\hline time & .777 & 2 & .388 & 388.872 & .000 \\
\hline age ${ }^{*}$ treatment & .043 & 2 & .022 & 21.544 & .000 \\
\hline age $^{*}$ time & .073 & 2 & .036 & 36.395 & .000 \\
\hline treatment $*$ time & .083 & 4 & .021 & 20.737 & .000 \\
\hline $\begin{array}{l}\text { age * treatment } \\
\text { * time }^{\text {time }}\end{array}$ & .012 & 4 & .003 & 3.085 & .023 \\
\hline Error & .054 & 54 & .001 & & \\
\hline Total & 5.765 & 72 & & & \\
\hline Corrected total & 1.455 & 71 & & & \\
\hline
\end{tabular}

${ }^{a} R^{2}=.963$ (Adjusted $R^{2}=.951$ )

TV in the tested groups (CA and PTH groups) as compared to the WT group at all tested time in both ages.

\section{Angiogenesis and osteoblasts in the adult CA mice and adult PTH mice were greater than in the adult WT mice but without statistical difference}

On days 7, 14, and 21 after fracture, the mRNA expression levels of $\beta$-catenin in the femur fractures of adult CA mice and adult PTH mice were higher than in adult WT mice, and the expression level of $\beta$-catenin was higher in adult CA mice than in adult PTH mice (Fig. 3a). On days 7, 14, and 21 after fracture, PTH1R mRNA expression levels in the femoral metaphyseal fracture region of adult PTH mice were higher than in adult CA and adult WT mice (Fig. 3b). RUNX2 mRNA expression levels in the adult PTH mouse fracture defect area were higher than in the adult WT mice on the 7th and 14th days after the fracture, and the RUNX2 mRNA was higher in the adult CA mouse than in adult WT mice on post-operative day 14 . No significant differences were found between the adult CA mice and adult PTH mice at the three time points (Fig. 3c). OCN mRNA expression levels in the adult PTH mouse fracture defect area were higher than in the adult WT mice on the 7th, 14th and 21th days after the fracture, and the OCN mRNA was higher in the adult CA mouse than in adult WT mice on post-operative day 14 (Fig. 3d). VEGF mRNA expression levels in the adult PTH mouse fracture defect area were higher than in the adult WT mice on the 14th and 21th days after the fracture, and the 


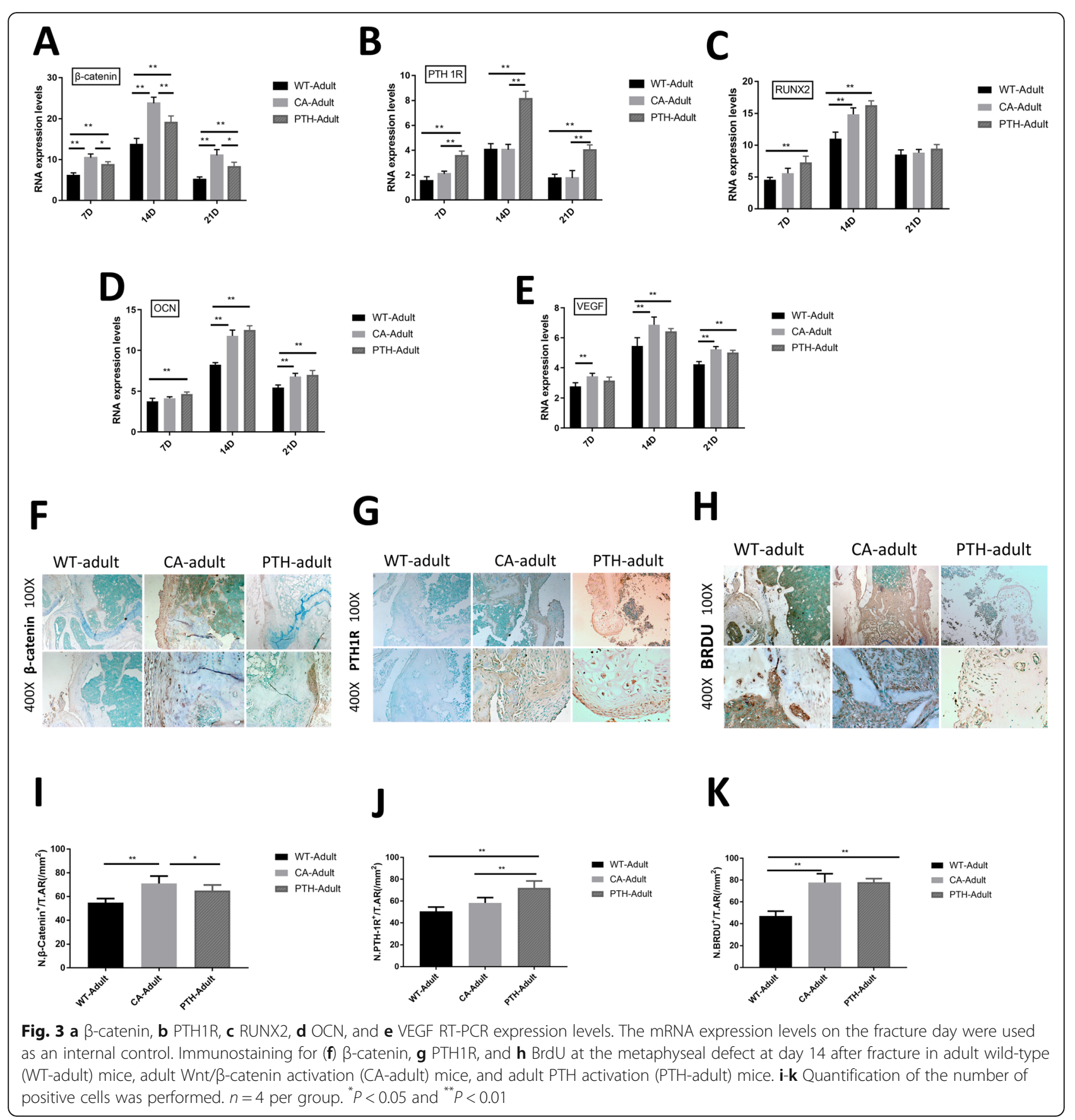

VEGF mRNA was higher in the adult CA mouse than in adult WT mice at the three time points (Fig. 3e). Immunohistochemical staining showed that the number of $\beta$ catenin-positive cells in the femoral defects of adult CA mice was greater than in the adult WT mice and adult PTH mice on post-operative day 14 (Fig. 3f and i). On day 14 post-fracture, PTH1R-positive cells in the femur defects of adult PTH mice were more abundant than PTH1R-positive cells in adult WT mice and adult CA mice (Fig. 3g and j). On the 14th day after the fracture, the number of BrdU-positive cells in the defects of adult CA mice and adult PTH mice was greater than in adult WT mice, but there was no statistical difference between adult CA mice and adult PTH mice (Fig. 3h and k).

By observing the immunohistochemical staining of the metaphysis of the femur, it was found that on day 14 after the fracture, the numbers of MMP9-positive cells (Fig. 4a and g) and VEGF-positive cells in the defects of adult CA mice and adult PTH mice (Fig. $4 \mathrm{~b}$ and The number of $\mathrm{H}$ ) were greater than the number in adult 


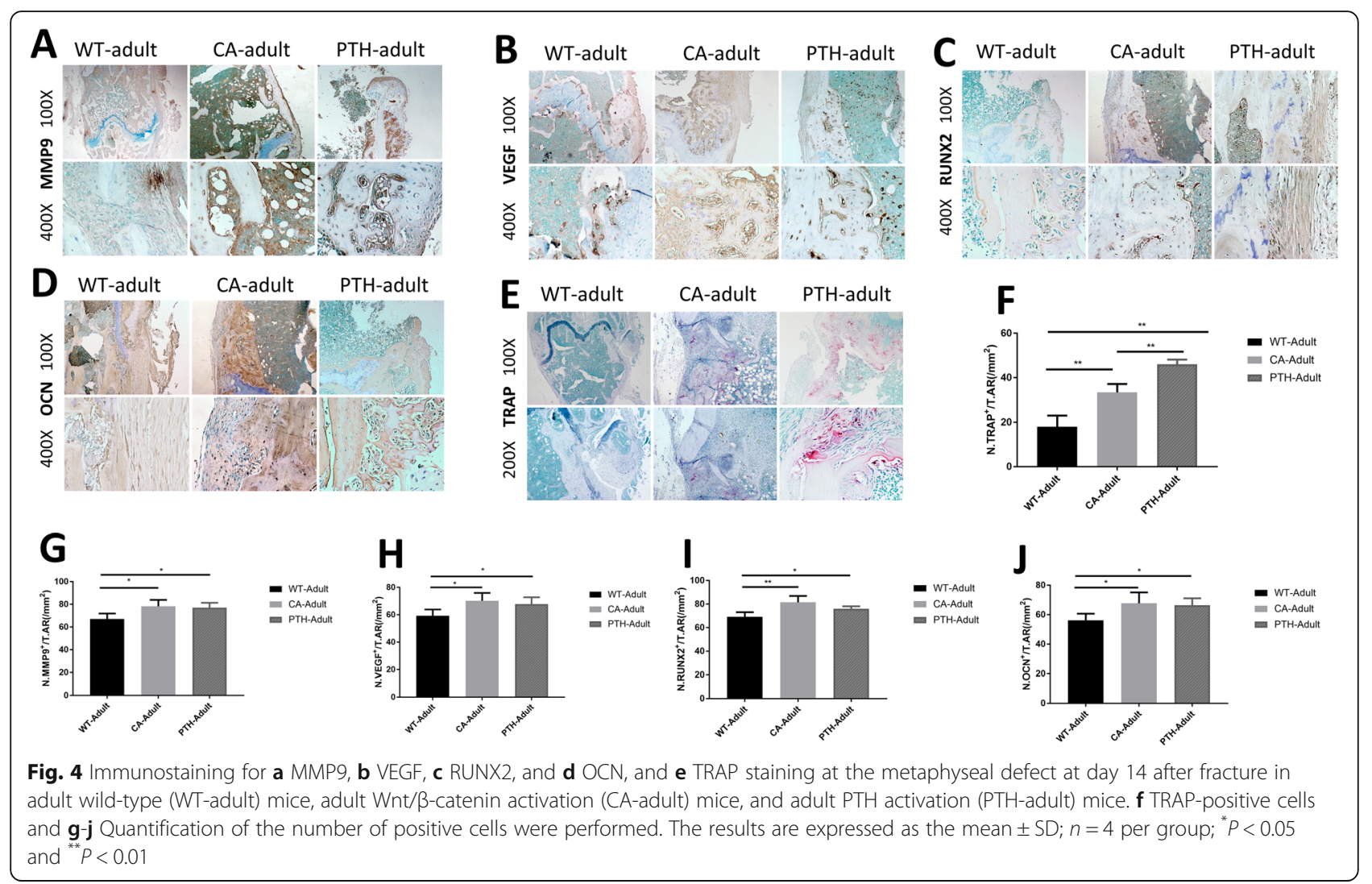

WT mice. Our results also found that the number of RUNX2-positive cells (Fig. 4c and i) and OCN-positive cells in the fracture defects of adult CA mice and adult PTH mice on day 14 after fracture (Fig. $4 \mathrm{~d}$ and j) were more than that in the adult WT mice. However, there was no significant difference in the numbers of MMP9-, VEGF-, RUNX2-, and OCN-positive cells in the defects between adult CA mice and adult PTH mice, and these indexes are important for fracture healing.

On post-operative day 14, TRAP staining showed that the number of TRAP-positive cells in the femoral metaphyseal fracture of adult PTH mice was higher than in adult WT mice and adult CA mice, and the number of TRAP-positive cells in adult CA mice was higher than in adult WT mice (Fig. 4e and f).

\section{Angiogenesis and osteoblasts in the aged CA mice and aged PTH mice were greater than in the aged WT mice and were greater in the aged CA mice than in the aged PTH mice}

RT-PCR experiments showed that the expression of $\beta$ catenin mRNA in aged CA mice was higher than in aged WT mice and aged PTH mice on days 7, 14, and 21 days after fracture, and was higher in PTH mice than in WT mice on the 21st day after fracture (Fig. 5a). On day 14 and day 21 after fracture, the expression level of PTH1R mRNA in the femoral metaphyseal fracture of aged PTH mice was higher than in aged CA mice and aged WT mice, and on the 14th day after fracture the mRNA expression level of PTH1R in aged CA mice was higher than in aged WT mice (Fig. 5b). RUNX2 mRNA expression was observed in the femoral metaphyseal fracture area. On days 7 and 14 after fracture, it was higher in the aged CA and PTH mice than in the age WT mice, and was higher in the aged CA mice than in the PTH mice (Fig. 5c). OCN mRNA expression levels in the aged PTH mouse fracture defect area were higher than in the aged WT mice, and the OCN mRNA was higher in the aged CA mouse than in aged WT and PTH mice at the three time points (Fig. 3d). The VEGF mRNA was higher in the aged CA mouse than in aged WT and PTH mice at the three time points (Fig. 3e).

On post-operative day 14, immunohistochemical staining showed that the number of $\beta$-catenin-positive cells in the femoral fracture defect of the aged CA mice was higher than in the aged WT mice and aged PTH mice (Fig. $5 \mathrm{f}$ and i). On post-operative day 14, the number of PTH1R-positive cells in the femur fracture defect of the aged PTH mice was higher than the aged WT mice and aged CA mice (Fig. 5g and j). On post-operative day 14, the number of BrdU-positive cells in the femur fracture defect of the aged CA mice and aged PTH mice was higher than in the aged WT mice, and the number of 


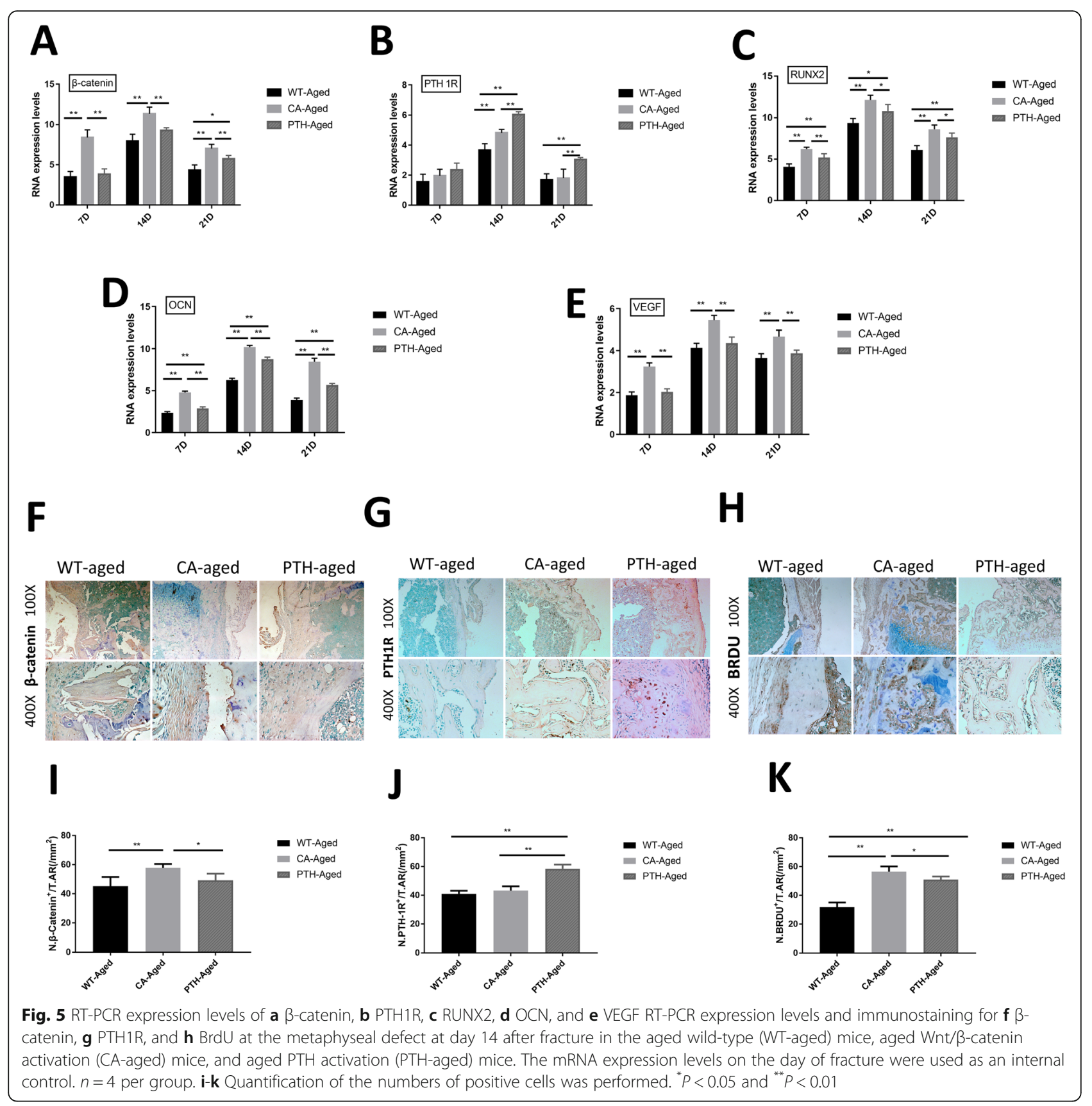

BrdU-positive cells in the aged CA mice was higher than that in the aged PTH mice (Fig. 5h and k).

Development of the microcirculation in the femoral metaphyseal fracture was observed by tissue immunohistochemical staining. MMP9-positive cells were found in the femoral fracture defects of aged CA mice and aged PTH mice on the 14th day after fracture (Fig. 6a and g). The number of VEGF-positive cells (Fig. $6 \mathrm{~b}$ and $\mathrm{h}$ ) in the aged CA mice and aged PTH mice was greater than in the aged WT mice, and there were more in the PTH mice than in the aged CA mice. On the 14th day after the fracture, the number of RUNX2-positive cells (Fig. $6 \mathrm{c}$ and i) and OCN-positive cells (Fig. $6 \mathrm{~d}$ and $\mathrm{j}$ ) in the femur fracture defect of the aged CA mice and aged PTH mice was higher than in the aged WT mice, and the aged CA mice had more RUNX2- and OCN-positive cells than the aged PTH mice.

TRAP staining showed that the number of TRAPpositive cells in the femoral metaphyseal fracture of aged PTH mice was higher than in the aged CA mice and aged WT mice, and more in the aged CA mice than in the aged WT mice (Fig. 6e and f). 


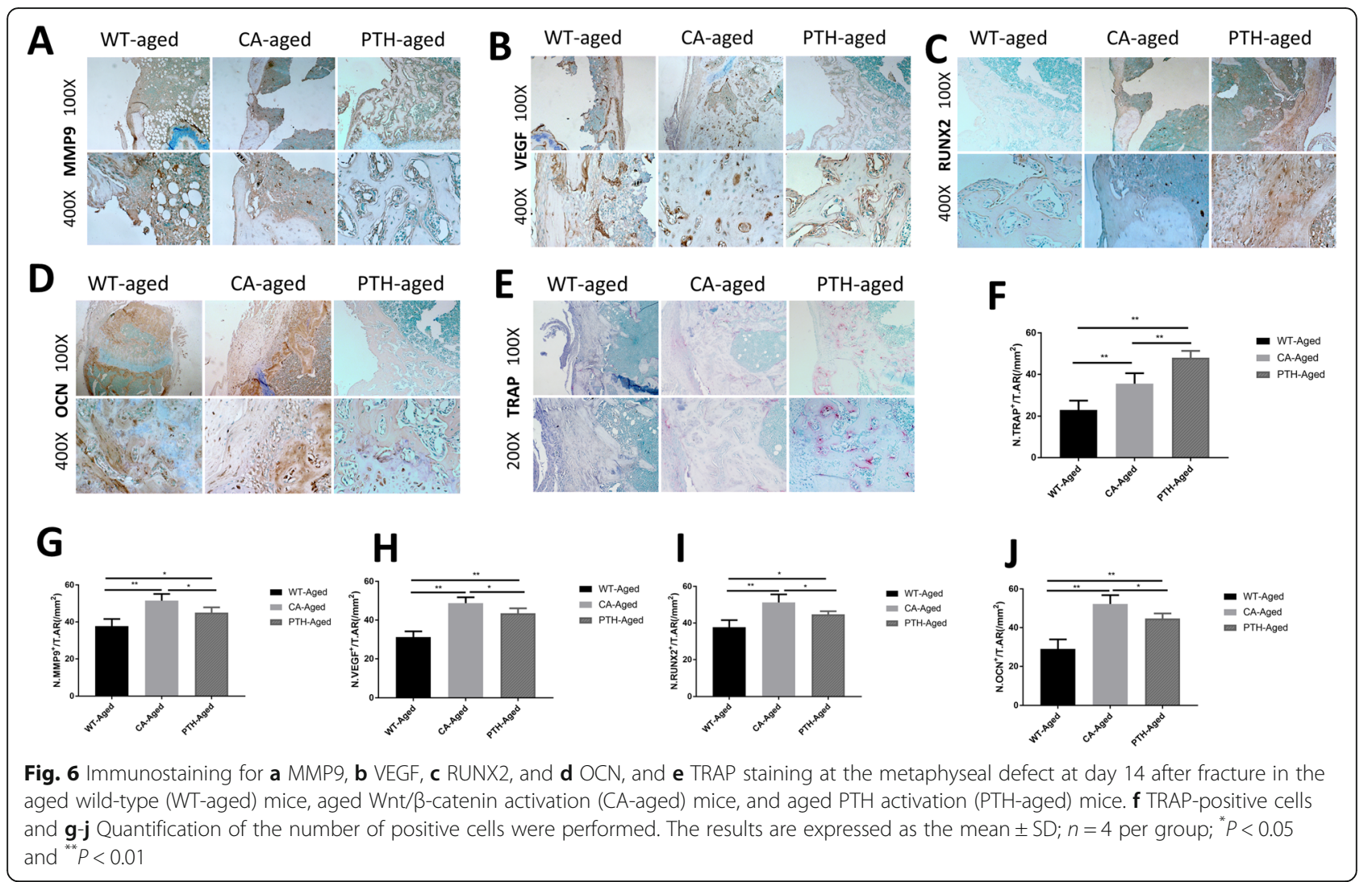

\section{Discussion}

To form new bone and remodel, fracture healing requires a series of complex physiological changes [29]. Fractures result in a continuous middle segment of the bone and vascular damage. Fracture healing includes three main stages: inflammation, repair, and remodeling. After the fracture occurs, the fracture site forms a hematoma and releases inflammatory molecules that stimulate mesenchymal stem cells to migrate and aggregate, new microcirculation and microvessels to form, and osteoblasts to differentiate into bone cells. Finally, through deposition, remodeling forms cortical or cancellous bone [30]. It also involves hematopoiesis in the bone marrow, immune inflammatory cells, microcirculation formation, aggregation and differentiation of mesenchymal stem cells (MSC), and activation of multiple signaling molecules that regulate a cascade of events including cell migration, proliferation, differentiation, enhancement, and inhibition, as well as extracellular protein synthesis, which in turn affects osteoblast and chondrocyte differentiation [31, 32]. Microcirculation and the formation of osteoblasts and collagen fibers are important factors in the healing process of fractures.

In recent years, the $\mathrm{Wnt} / \beta$-catenin signaling pathway and PTH signaling pathway have been the research directions for promoting fracture healing. Activation of the
Wnt/ $\beta$-catenin signaling pathway promotes cell proliferation, osteogenic differentiation, microcirculation, and proper inhibition of osteoblasts; angiogenesis and microcirculation are important for fracture healing [33, 34]. Many scholars have found that activation of the Wnt signaling pathway promotes microcirculation formation [35], particularly through VEGF and MMP9 [36], which have very large effects on fracture healing [37]. In our experiments, both adult and aged CA mice showed better microcirculation formation and osteogenic differentiation than the adult and aged WT mice.

In our experiments we found activation of the Wnt signaling pathway promoted the increase of VEGF mRNA expression, and the increase of VEGF and MMP9 expression in fracture defect, similar to the findings of Karki S [35, 38]. Activation of the Wnt signaling pathway promoted the increase in OCN and RUNX2 expression, thereby promoting the differentiation of osteoblasts [39-41].

Teriparatide is a recombinant human parathyroid hormone that has anabolic effects on bone and increases osteoblast activity and bone mass [42]. Because of these effects, it has recently been studied as an application to promote fracture healing. Intermittent low doses of PTH (1-34) can enhance chondrogenesis and accelerate cartilage differentiation and increase the proliferation of chondrogenic cells and type II collagen. Synthesis leads 
to the formation of larger cartilage calli [43, 44]. PTH can also induce cartilage callus to be converted into bone. There are also studies suggesting that PTH can modulate key molecular components of the Wnt signaling pathway during early fracture [45], promote bone morphogenetic protein signaling [46], inhibit the Notch signaling pathway [47], and aggregate mesenchymal stem cells into osteoblasts. It plays an important role in the differentiation of chondrocytes [48]. It was also found in our experiments that $\beta$-catenin was elevated during fracture healing in both adult and aged PTH mice. Adult and aged PTH mice also had more microcirculation and osteogenic differentiation than WT mice.

In our experiments, we found that activation of the Wnt $/ \beta$-catenin and PTH signaling pathways in adult mice promoted the formation of osteogenesis and microcirculation and promoted cell proliferation and progression compared with WT mice. Bone differentiation promotes fracture healing. Activation of $\mathrm{Wnt} / \beta$-catenin and $\mathrm{PTH}$ signaling pathways led to increased proliferation, increased expression of RUNX2 and OCN in osteoblasts, and elevated VEGF and MMP9 associated with microcirculation. Finally, morphologically, a similar promotion effect was obtained. Although Wnt/B-catenin, which inhibits osteoclasts, was activated, few TRAP cells were found in the femoral metaphyseal fracture defect than that in WT mice. The PTH mice had more osteoclasts in the fracture defect than that in WT mice and CA mice, but this did not change the morphological tendency of the adult CA and PTH mice to heal earlier. This indicates that the role of bone formation is important in the early stages of fracture healing, and the effect of osteoclasts does not lead to changes in fracture healing.

Age is a detrimental factor in fracture healing. The microenvironment of bone marrow changes with age, which may be detrimental to the proliferation of MSC or may lead to the differentiation of MSC into different cells. The differentiation of bone marrow fat increases with age, which is not conducive to osteoblast formation $[49,50]$. Bergman et al. [51] found that the decrease in the number and proliferation potential of mesenchymal stem cells with age may be responsible for the decrease in the number and function of osteoblasts with age. Increased trabecular bone loss with age leads to thinning between trabecular plates, perforation and connectivity, and reduced abundance of cancellous bone, which can also adversely affect fracture healing [17].

Delayed healing in elderly patients is attributed to the lower ability of mesenchymal progenitor cells to divide and differentiate, decreased micro-angiogenic capacity, and decreased growth factor levels [52]. Some studies investigating the biomechanical advances in fractures have shown that older rats require more time to heal and restore intact mechanical strength [53-55]. Osteoporosis not only reduces bone mass but also changes the composition and structure of bone tissue [56-58]. Hormonal circulation levels change, especially the postmenopausal estrogen levels, and bone mass decreases with age. The decreased bone mass may also be due to a decrease in the anabolism of mechanical load due to decreased levels of physical activity [59].

Although the ability of fracture healing in aged mice is reduced, the corresponding molecular mechanisms and procedures still exist. In our study, the $\mathrm{Wnt} / \beta$-catenin and PTH signaling pathways were activated to promote fracture healing, including microcirculation and osteogenesis. Activation of the Wnt/ $\beta$-catenin signaling pathway and PTH signaling pathway in aged mice resulted in increased proliferation and increased expression of RUNX2 and OCN in osteoblasts, and VEGF and MMP9 associated with microcirculation compared with WT mice. Moreover, activation of the $\mathrm{Wnt} / \beta$-catenin signaling pathway in older mice had more proliferation (BrdU expression) than with the activation of the PTH signaling pathway, increased RUNX2 and OCN expression in osteoblasts, and elevated VEGF and MMP9 associated with microcirculation. Morphologically, it was also found that activation of the $\mathrm{Wnt} / \beta$-catenin signaling pathway in aged mice resulted in better fracture healing than activation of the PTH signaling pathway. Although activation of the PTH signaling pathway led to more osteoclasts in the femoral fracture defect than in the WT mice, the healing rate was still faster than in the WT mice. This indicates that the effect of changes in osteoclasts on the rate of fracture healing in adult mice was not as great as the effects of osteoblasts and microcirculation changes.

We considered that activation of the $\mathrm{Wnt} / \beta$-catenin signaling pathway in older mice promoted fracture healing better than activation of the PTH signaling pathway, possibly because of the reduction in stem cells at the cancellous bone of aged mice. The microcirculation of the blood supply was reduced, and there were not enough stem cells in the fracture area to differentiate into microvessels and osteoblasts, which would not only lead to a decrease in bone density and bone quality but also a decrease in the formation of osteoblasts and microcirculation. Activation of the $\mathrm{Wnt} / \beta$-catenin signaling pathway in the aged mice increased proliferation, osteogenic differentiation of mesenchymal stem cells, and angiogenesis. The PTH signaling pathway stimulated osteogenesis through osteoclast formation. When there were not enough stem cells in the metaphysis of the aged mice, the indirect stimulation of activation of the PTH signaling pathway did not produce more osteoblasts and microcirculation. The role of microcirculation in the healing of aged fractures is important, and the microcirculation has a considerable role in promoting the formation of osteogenesis. Activation of the Wnt/B- 
catenin signaling pathway in aged mice led to stronger proliferation, osteogenesis, and microcirculation formation, which promoted the early fracture healing better than with the activation of the PTH signaling pathway.

During fracture healing, the relevant cellular molecules from the soft tissue, endothelium, and blood vessels need to reach the fracture site, in which the trabecular bone in the cancellous bone is surrounded by the bone marrow. The stem cells are relatively easy to obtain during healing and differentiate into osteoblasts and microvessels. In adult mice, there are sufficient microcirculation and stem cells in the cancellous bone for transformation, irrespective of whether the $\mathrm{Wnt} / \beta$-catenin signaling pathway is activated to directly promote osteogenic differentiation and microcirculation or the PTH signaling pathway is activated to promote osteogenic differentiation indirectly. And, it does not cause too much difference in promoting fracture healing.

\section{Conclusion}

Although activation of the Wnt/ $\beta$-catenin signaling pathway in adulthood shows some advantages over activation of the PTH signaling pathway, there was no statistically significant difference; in the older animal, it was significantly better than the activation of the PTH signaling pathway. This may prompt us to consider that using drugs related to the Wnt signaling pathway may be better in the early stages of fracture healing in the elderly.

\section{Abbreviations \\ BrdU: 5'-bromo-2-deoxyuridine; BV/TV: Bone volume to total volume; GAPDH: Glyceraldehyde-3-phosphate dehydrogenase; H\&E: Hematoxylin- eosin; IHC: Immunohistochemistry; MMP9: Matrix metallopeptidase 9; OCN: Osteocalcin; RT-PCR: Real-time polymerase chain reaction; RUNX2: Runt-related transcription factor 2; TRAP: Tartrate-resistant acid phosphatase; VEGF: Vascular endothelial growth factor; WT: Wild-type}

\section{Acknowledgements}

There is International Science Editing (http://www. internationalscienceediting.com) for editing this manuscript. Special thanks to Pro. Jianquan Feng (Department of Biomedical Sciences, Baylor Dental University, USA) for kindly providing the transgenic mice.

\section{Authors' contributions}

LDC: the conception and design of the work; the acquisition, analysis, and interpretation of data; drafting the manuscript. ZZW: the design; the acquisition and interpretation of data. QH: the interpretation of data. YJZ: the interpretation of data. YL: the interpretation of data. HHS: the interpretation of data; drafting the manuscript. CSX: the interpretation of data. BQW: the interpretation of data. ZYF: the conception and design of the work; the interpretation of data. All authors read and approved the final manuscript.

\section{Funding}

No funding was received.

\section{Availability of data and materials}

The datasets used and/or analyzed during the current study are available from the corresponding author on reasonable request.

\section{Ethics approval and consent to participate}

All animal procedures were approved by the Laboratory Animal Welfare and Ethics Committee of the Third Military Medical University of China and were conducted in accordance with procedures approved by the institution.
Consent for publication

Not applicable.

\section{Competing interests}

The authors declare that they have no competing interests.

Received: 24 October 2019 Accepted: 12 February 2020

Published online: 19 February 2020

\section{References}

1. van Staa TP, Dennison EM, Leufkens HG, Cooper C. Epidemiology of fractures in England and Wales. Bone. 2001;29(6):517-22.

2. Calori GM, Albisetti W, Agus A, lori S, Tagliabue L. Risk factors contributing to fracture non-unions. Injury. 2007:38(Suppl 2):S11-8.

3. Bliuc D, Nguyen TV, Eisman JA, Center JR. The impact of nonhip nonvertebral fractures in elderly women and men. J Clin Endocrinol Metab. 2014;99(2):415-23.

4. Minns Lowe CJ, Toye F, Barker KL. Men's experiences of having osteoporosis vertebral fractures: a qualitative study using interpretative phenomenological analyses. Osteoporos Int. 2019;30(7):1403-12.

5. Dovjak P. Diagnostics and treatment of osteoporosis in patients over 65 years old: Current status and future perspectives. Z Gerontol Geriatr. 2019; 52(5):421-7.

6. Araujo AB, Travison TG, Harris SS, Holick MF, Turner AK, McKinlay JB. Race/ ethnic differences in bone mineral density in men. Osteoporos Int. 2007; 18(7):943-53.

7. Cauley JA, Fullman RL, Stone KL, Zmuda JM, Bauer DC, Barrett-Connor E, Ensrud K, Lau EM, Orwoll ES. Factors associated with the lumbar spine and proximal femur bone mineral density in older men. Osteoporos Int. 2005; 16(12):1525-37.

8. Makitie RE, Niinimaki T, Nieminen MT, Schalin-Jantti C, Niinimaki J, Makitie O Impaired WNT signaling and the spine-heterozygous WNT1 mutation causes severe age-related spinal pathology. Bone. 2017;101:3-9.

9. Dimitriou R, Jones E, McGonagle D, Giannoudis PV. Bone regeneration: current concepts and future directions. BMC Med. 2011;9:66.

10. Liedert A, Rontgen V, Schinke T, Benisch P, Ebert R, Jakob F, Klein-Hitpass L, Lennerz JK, Amling M, Ignatius A. Osteoblast-specific Krm2 overexpression and Lrp5 deficiency have different effects on fracture healing in mice. PLoS One. 2014;9(7):e103250.

11. Skripitz R, Aspenberg P. Early effect of parathyroid hormone (1-34) on implant fixation. Clin Orthop Relat Res. 2001:392(392):427-32.

12. Skripitz R, Aspenberg P. Implant fixation enhanced by intermittent treatment with parathyroid hormone. J Bone Joint Surg. 2001;83(3):437-40.

13. Agholme F, Macias B, Hamang M, Lucchesi J, Adrian MD, Kuhstoss S, Harvey A, Sato M, Aspenberg P. Efficacy of a sclerostin antibody compared to a low dose of PTH on metaphyseal bone healing. J Orthop Res. 2013;32(3):471-6.

14. Sandberg O, Macias BR, Aspenberg P. Low dose PTH improves metaphyseal bone healing more when muscles are paralyzed. Bone. 2014;63(3):15-9.

15. Nakajima A, Shimoji N, Shiomi K, Shimizu S, Moriya H, Einhorn TA. Mechanisms for the enhancement of fracture healing in rats treated with intermittent low-dose human parathyroid hormone (1-34). J Bone Mineral Res. 2002;17(11):2038-47.

16. Xie Y, Yi L, Weng T, Huang J, Luo F, Jiang W, Xian CJ, Du X, Chen L. Fibroblast growth factor receptor 3 deficiency does not impair the Osteoanabolic action of parathyroid hormone on mice. Int J Biol Sci. 2016; 12:990-9.

17. Chen H, Sun X, Yin L, Chen S, Zhu Y, Huang J, Jiang W, Chen B, Zhang R, Chen L. PTH 1-34 ameliorates the osteopenia and delayed healing of stabilized tibia fracture in mice with Achondroplasia resulting from gain-offunction mutation of FGFR3. Int J Biol Sci. 2017;13(10):1254-65.

18. Li J, Bao Q, Chen S, Liu H, Feng J, Qin H, Li A, Liu D, Shen Y, Zhao Y. Different bone remodeling levels of trabecular and cortical bone in response to changes in Wnt/ $\beta$-catenin signaling in mice. J Orthop Res. 2016:35(4):812-9.

19. Bao Q, Chen S, Qin H, Feng J, Liu H, Liu D, Li A, Shen Y, Zhong X, Li J. Constitutive $\beta$-catenin activation in osteoblasts impairs terminal osteoblast differentiation and bone quality. Exp Cell Res. 2016;350(1):123-31.

20. Kim JB, Leucht P, Lam K, Luppen C, Ten BD, Nusse R, Helms JA. Bone regeneration is regulated by wnt signaling. J Bone Miner Res. 2007:22(12): 1913-23. 
21. Agholme F, Li XH, Ke HZ, Aspenberg P. Sclerostin antibody treatment enhances metaphyseal bone healing in rats. J Bone Miner Res. 2010;25(11): 2412-8.

22. Mcgeelawrence ME, Ryan ZC, Carpio LR, Kakar S, Westendorf JJ, Kumar R. Sclerostin deficient mice rapidly heal bone defects by activating $\beta$-catenin and increasing intramembranous ossification. Biochemical Biophysical Res Communications. 2013;441(4):886-90.

23. Bernhardsson M, Aspenberg P. Osteoblast precursors and inflammatory cells arrive simultaneously to sites of a trabecular-bone injury. Acta Orthop. 2018; 89(4):457-61.

24. Xie C, Liang B, Xue M, Lin AS, Loiselle A, Schwarz EM, Guldberg RE, O'Keefe $\mathrm{RJ}$, Zhang $X$. Rescue of impaired fracture healing in COX-2-/- mice via activation of prostaglandin E2 receptor subtype 4. Am J Pathol. 2009;175(2): $772-85$

25. Gao F, LV TR, Zhou JC, Qin XD. Effects of obesity on the healing of bone fracture in mice. J Orthop Surg Res. 2018;13(1):145.

26. Gaur T, Lengner CJ, Hovhannisyan H, Bhat RA, Bodine PV, Komm BS, Javed A, van Wijnen AJ, Stein JL, Stein GS, et al. Canonical WNT signaling promotes osteogenesis by directly stimulating Runx2 gene expression. J Biol Chem. 2005;280(39):33132-40.

27. Chen S, Feng J, Bao Q, Li A, Zhang B, Shen Y, Zhao Y, Guo Q, Jing J, Lin S. Adverse effects of osteocytic constitutive activation of $B$-catenin on bone strength and bone growth. J Bone Min Res. 2015;30(7):1184-94.

28. Chen T, Li J, Cordova LA, Liu B, Mouraret S, Sun Q, Salmon B, Helms J. A WNT protein therapeutic improves the bone-forming capacity of autografts from aged animals. Sci Rep. 2018;8(1):119.

29. McKibbin B. The biology of fracture healing in long bones. J Bone Joint Surg Br. 1978;60-b(2):150-62.

30. Marsell R, Einhorn TA. The biology of fracture healing. Injury. 2011:42(6):551-5.

31. Li X, Quigg RJ, Zhou J, Ryaby JT, Wang H. Early signals for fracture healing. J Cell Biochem. 2005;95(1):189-205.

32. Lombardo F, Komatsu D, Hadjiargyrou M. Molecular cloning and characterization of mustang, a novel nuclear protein expressed during skeletal development and regeneration. FASEB J. 2004;18(1):52-61.

33. Carano RA, Filvaroff EH. Angiogenesis and bone repair. Drug Discov Today. 2003:8(21):980-9.

34. Saran U, Gemini Piperni S, Chatterjee S. Role of angiogenesis in bone repair. Arch Biochem Biophys. 2014;561:109-17.

35. Olsen JJ, Pohl SO, Deshmukh A, Visweswaran M, Ward NC, Arfuso F, Agostino M, Dharmarajan A. The role of Wnt Signalling in angiogenesis. Clin Biochem Rev. 2017;38(3):131-42.

36. Choi SH, Kim H, Lee HG, Kim BK, Park JY, Kim DY, Ahn SH, Han KH, Kim SU. Dickkopf-1 induces angiogenesis via VEGF receptor 2 regulation independent of the Wnt signaling pathway. Oncotarget. 2017:8(35):58974-84.

37. Hu K, Olsen BR. The roles of vascular endothelial growth factor in bone repair and regeneration. Bone. 2016;91:30-8.

38. Karki S, Ngo DTM, Farb MG, Park SY, Saggese SM, Hamburg NM, Carmine B, Hess DT, Walsh K, Gokce N. WNT5A regulates adipose tissue angiogenesis via antiangiogenic VEGF-A165b in obese humans. Am J Physiol Heart Circ Physiol. 2017;313(1):H200-6.

39. Haxaire C, Hay E, Geoffroy V. Runx2 controls bone Resorption through the Down-regulation of the Wnt pathway in osteoblasts. Am J Pathol. 2016; 186(6):1598-609.

40. Rudnicki MA, Williams BO. Wht signaling in bone and muscle. Bone. 2015; 80:60-6.

41. Ryan ZC, Craig TA, Salisbury JL, Carpio LR, McGee-Lawrence M, Westendorf $\mathrm{J}$, Kumar R. Enhanced prostacyclin formation and Wht signaling in sclerostin deficient osteocytes and bone. Biochem Biophys Res Commun. 2014:448(1):83-8

42. Pietrogrande $L$, Raimondo $E$. Teriparatide in the treatment of non-unions: scientific and clinical evidences. Injury. 2013:44(Suppl 1):S54-7.

43. Milstrey A, Wieskoetter B, Hinze D, Grueneweller N, Stange R, Pap T, Raschke M, Garcia P. Dose-dependent effect of parathyroid hormone on fracture healing and bone formation in mice. J Surg Res. 2017;220:327-35.

44. Huang TW, Chuang PY, Lin SJ, Lee CY, Huang KC, Shih HN, Lee MS, Hsu RW, Shen WJ. Teriparatide improves fracture healing and early functional recovery in treatment of osteoporotic intertrochanteric fractures. Medicine (Baltimore). 2016;95(19):e3626.

45. Barnes GL, Einhorn TA. Enhancement of fracture healing with parathyroid hormone. Clin Rev Bone Min Metab. 2006:4(4):269-75.
46. Yu B, Zhao X, Yang C, Crane J, Xian L, Lu W, Wan M, Cao X. Parathyroid hormone induces differentiation of mesenchymal stromal/stem cells by enhancing bone morphogenetic protein signaling. J Bone Miner Res. 2012; 27(9):2001-14.

47. Zanotti S, Canalis E. Parathyroid hormone inhibits notch signaling in osteoblasts and osteocytes. Bone. 2017;103:159-67.

48. Lombardi G, Di Somma C, Rubino M, Faggiano A, Vuolo L, Guerra E, Contaldi P, Savastano S, Colao A. The roles of parathyroid hormone in bone remodeling: prospects for novel therapeutics. J Endocrinol Investig. 2011; 34(7 Suppl):18-22.

49. Beresford JN, Bennett JH, Devlin C, Leboy PS, Owen ME. Evidence for an inverse relationship between the differentiation of adipocytic and osteogenic cells in rat marrow stromal cell cultures. J Cell Sci. 1992;102(Pt 2): $341-51$

50. Burkhardt R, Kettner G, Bohm W, Schmidmeier M, Schlag R, Frisch B, Mallmann B, Eisenmenger W, Gilg T. Changes in trabecular bone, hematopoiesis and bone marrow vessels in aplastic anemia, primary osteoporosis, and old age: a comparative histomorphometric study. Bone. 1987;8(3):157-64.

51. Bergman RJ, Gazit D, Kahn AJ, Gruber H, McDougall S, Hahn TJ. Age-related changes in osteogenic stem cells in mice. J Bone Miner Res. 1996;11(5):568-77.

52. Gruber $\mathrm{R}$, Koch $\mathrm{H}$, Doll BA, Tegtmeier F, Einhorn TA, Hollinger JO. Fracture healing in the elderly patient. Exp Gerontol. 2006;41(11):1080-93.

53. Ekeland A, Engesoeter LB, Langeland N. Influence of age on mechanical properties of healing fractures and intact bones in rats. Acta Orthop Scand. 1982:53(4):527-34.

54. Bak $B$, Andreassen $\Pi$. The effect of aging on fracture healing in the rat. Calcif Tissue Int. 1989:45(5):292-7.

55. Strube P, Sentuerk U, Riha T, Kaspar K, Mueller M, Kasper G, Matziolis G, Duda GN, Perka C. Influence of age and mechanical stability on bone defect healing: age reverses mechanical effects. Bone. 2008;42(4):758-64.

56. Bailey AJ, Sims TJ, Ebbesen EN, Mansell JP, Thomsen JS, Mosekilde L. Agerelated changes in the biochemical properties of human cancellous bone collagen: relationship to bone strength. Calcif Tissue Int. 1999;65(3):203-10

57. Mosekilde L. Age-related changes in bone mass, structure, and strength-effects of loading. Z Rheumatol. 2000;59(Suppl 1):1-9.

58. Giannoudis P, Tzioupis C, Almalki T, Buckley R. Fracture healing in osteoporotic fractures: is it really different? A basic science perspective. Injury. 2007:38(Suppl 1):S90-9.

59. Villareal DT, Morley JE. Trophic factors in aging. Should older people receive hormonal replacement therapy? Drugs Aging. 1994;4(6):492-509.

\section{Publisher's Note}

Springer Nature remains neutral with regard to jurisdictional claims in published maps and institutional affiliations.

Ready to submit your research? Choose BMC and benefit from:

- fast, convenient online submission

- thorough peer review by experienced researchers in your field

- rapid publication on acceptance

- support for research data, including large and complex data types

- gold Open Access which fosters wider collaboration and increased citations

- maximum visibility for your research: over $100 \mathrm{M}$ website views per year

At $\mathrm{BMC}$, research is always in progress.

Learn more biomedcentral.com/submissions 